\title{
SAFETY/RELIABILITY ANALYSES OF GA AIRCRAFT IN DESIGN AND CERTIFICATION STAGE IN CZECH REPUBLIC
}

\section{J. Hlinka}

Institute of Aerospace Engineering, Brno University of Technology, Czech Republic, Technicka 2, Brno 61669. E-mail: hlinka@fme.vutbr.cz Received 16 July 2007, accepted 10 Oct 2007

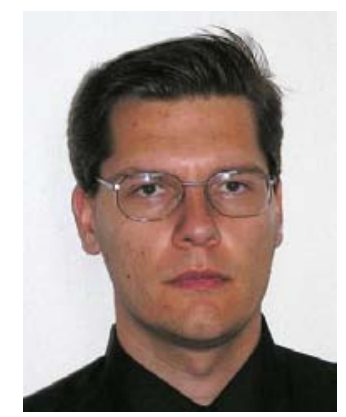

Jiri HLINKA, PhD Eng

Date and place of birth: 1978 in Brno, Czech Republic.

Education: 1996-2001 Brno University of Technology - Eng. (MSc.); 2001-2004 Brno University of

Technology, Faculty of Mech. Eng. - PhD.

Affiliations and functions: Since 2002, researcher in Aerospace Research Centre (Czech Republic); since 2002, lecturer in Institute of Aerospace Engineering; since 2004, assistant lecturer in Institute of Aerospace Engineering. Research interests: reliability of aircraft systems, with a focus on general aviation airplanes.

Publications: 19 articles and 15 research reports on the topic of interest.

Present position: assistant lecturer in the Institute of Aerospace Engineering (Brno University of Technology).

Abstract. The purpose of the paper was to provide the reader with basic insight into practical problems solved in the Czech aerospace industry and with a list of requirements and recommendations of civil airworthiness regulations on the field of reliability. This includes a short historical introduction, a list of basic requirements, and recommendations of the regulations for different aircraft categories. The general aviation category (sport airplanes and small transport airplanes) is covered in more depth. Recommended procedures for reliability analyses are also covered (with a focus on the design and certification process), including a brief summary of their utilization in the Czech aerospace industry. Special attention is paid on the activities of the Brno University of Technology (and its Institute of Aerospace Engineering). A practical example of safety assessment based on an electronic avionic system for small GA aircraft is also provided.

The paper is closed with a list of recommended documents (recommended by regulations and advisory circulars).

Keywords: safety assessment, reliability, aviation, aircraft, FMEA, RBD.

\begin{tabular}{|l|l|}
\hline Abbreviations: & $\mathbf{f}(\mathrm{x})$ - Probability density function \\
\hline CS - Certification Specifications & $\mathbf{R}$ - Reliability \\
FAR - Federal Aviation Regulation & L - Loads \\
FAA - Federal Aviation Administration & F(x) - Distribution function \\
GA - General Aviation & \\
HIRF - High Intensity Radiated Fields & \\
IAE - Institute of Aerospace Engineering & \\
IFR - Instrument Flight Rules & \\
TCAD - Traffic Collision Alerting Device & \\
\hline
\end{tabular}

\section{Introduction}

Safety has been one of the main objectives in the civil aviation since its early years. The term "acceptable level of safety" has changed with the time, moving towards higher levels (Fig 1). The reason for this was, among others, the introduction of transport airplanes for passengers, describes this process with the following words: "the same public that had sympathy for the tragic accidents of the first pioneers had no understanding for catastrophic accidents involving themselves") [1]. The airplanes built in the period between the world wars could be understood as relatively simple products (most aircraft had more or less similar structure comprised of a wing, fuselage, tail planes, landing gear, propulsion system, and a simple mechanical control system). Systems used in such aircraft were often mechanical (and they were never as complex as their modern equivalents). Thus, it was possible to create "deterministic" design procedures for such airplanes. Design procedures usually included simplified relations for estimation of flight loads and the definition of safety coefficients. Structures designed for higher loads than normal operational loads were considered safe/reliable. Calculations were usually verified by structural tests. The feasibility of the 
procedures described was proved by historical experiences with similar structures (designed according to the same requirements).

After the Second World War, the complexity of new aircraft started to increase. Aircraft had new, more complex systems (including hydraulic, electric, and avionic) and old design procedures were not sufficient for the design of new systems. It was necessary to find new, more general, approaches for design. Such procedures were called safety analyses, but in fact were composed of different types of reliability analyses (probability of events with different effects was calculated).
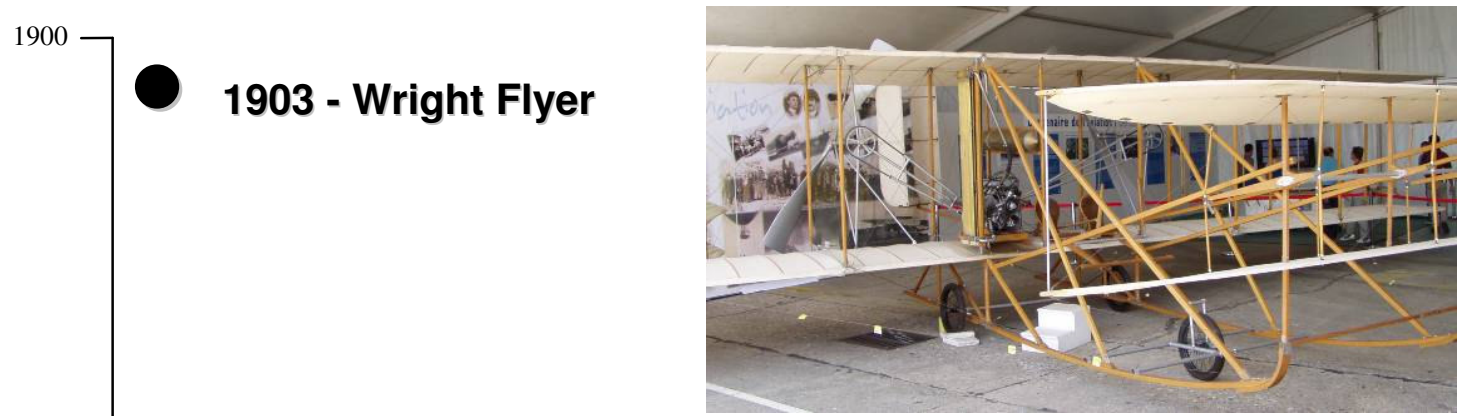

Simple design without fail-safe systems (or any other kind of redundancy). The only safety/reliability procedure was a simple structural test (structure was loaded to higher-than-expected loads).

1937 - DC3

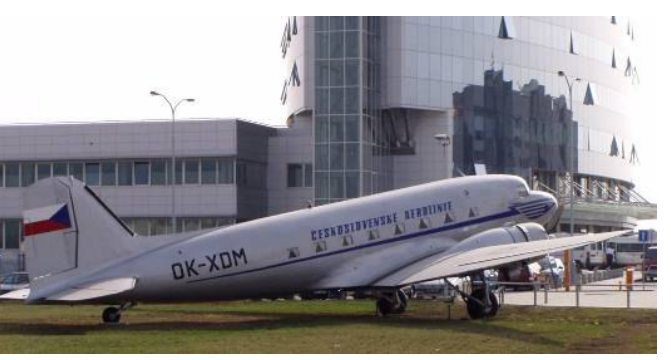

This aircraft was designed in compliance with regulatory requirements (minimal loads specified in regulations and safety coefficients were applied). (20) Selected systems had a fail-safe design. The design was validated by a structural test. The aircraft also had specified maintenance procedures.

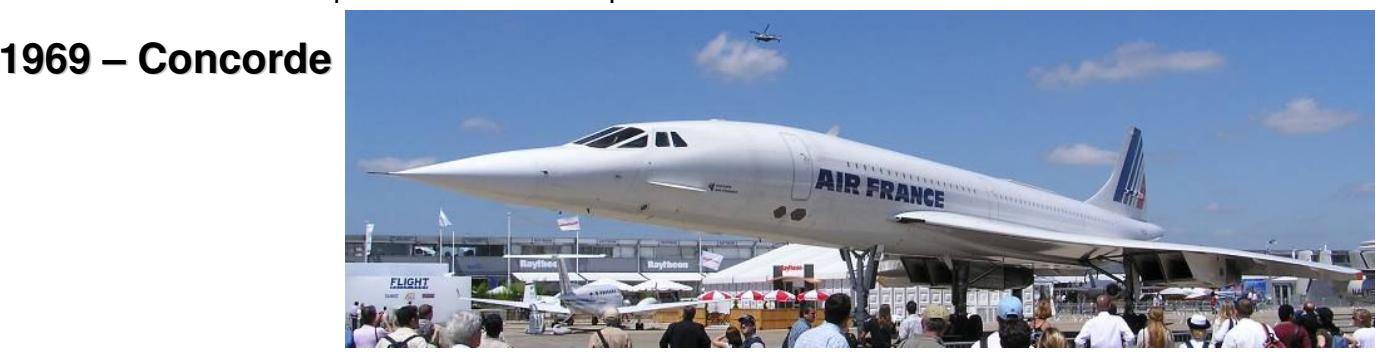

An aircraft with a complex structure and systems (including hydraulic and electronic systems). It has a great number of systems with back-up (safety/reliability analyses were made for selected systems). The design was validated by a wide range of tests (structural static and fatigue tests, reliability tests). Detailed maintenance procedures and operational data acquisition procedures were developed for the type.

Fig 1. Historical development of aircraft design

\section{Requirements of the regulation}

Safety/reliability analyses were included in regulation requirements in the 1960s. First of all, reliability requirements for transport airplanes were produced (FAR-25), followed by requirements for GA (general aviation) airplanes (FAR-23) and helicopters (FAR-27, FAR-29) [11, 3, 1, 2]. Based on historical experiences, different aircraft categories had different requirements. As a matter of fact, the bigger an aircraft is, the higher the safety demands are (including allowable probabilities of catastrophic events (Fig 2).

As mentioned earlier, safety requirements imposed on systems are, to the great extent, reliability requirements. This type of requirements is valid for "Systems, Equipment and Installations". "An acceptable level of safety" of structural parts of an aircraft is ensured using deterministic procedures (use of safety coefficients and structural tests). Explanations provided in this paper are based on the US regulation FAR (European regulations, CS, are fully compatible). The certification 
standards mentioned are widely accepted throughout the entire world.

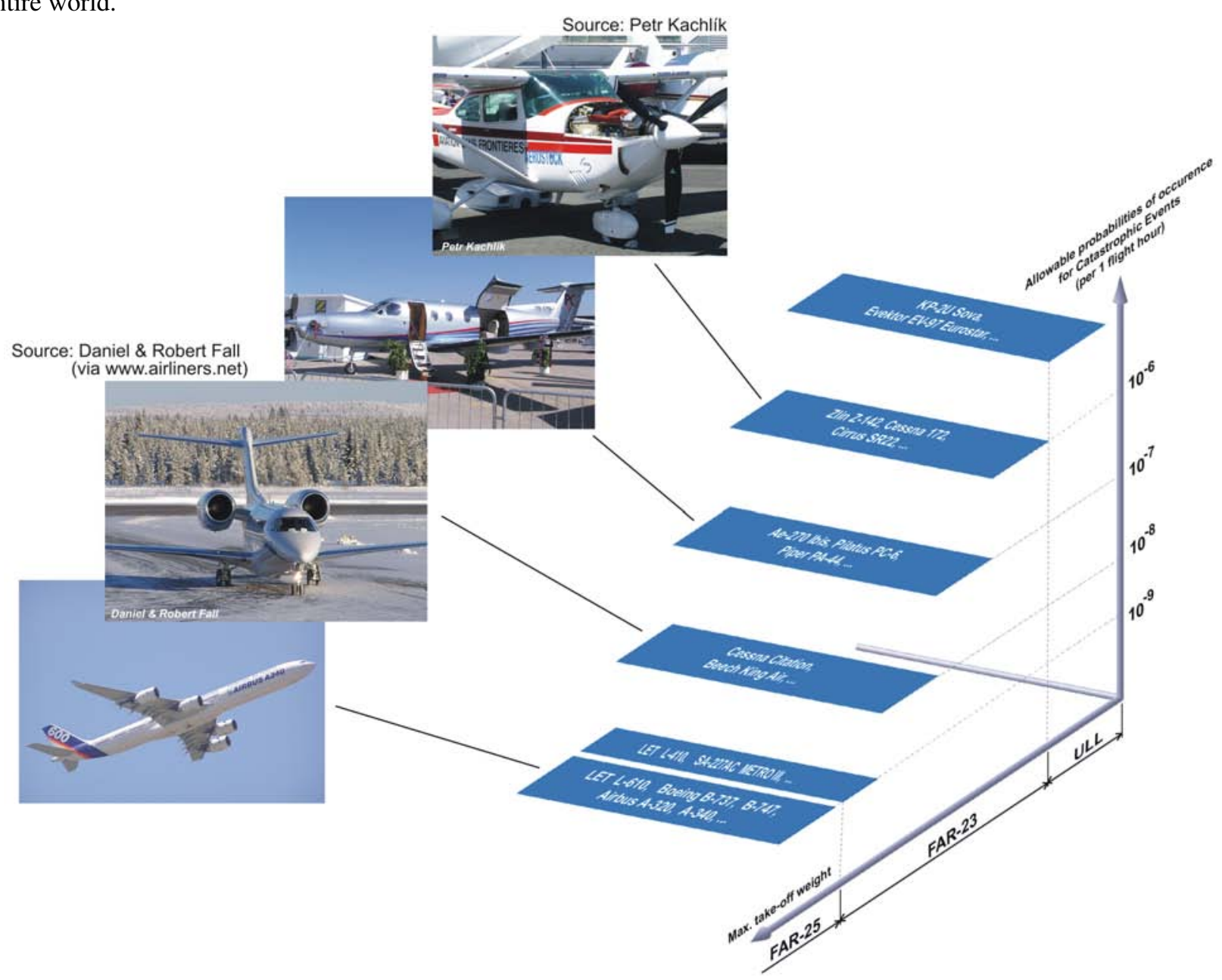

Fig 2. Simplified illustration of regulatory requirements for different categories of aircraft (maximum allowable probabilities of catastrophic failures per one flight hour)

Transport category airplanes are designed in accordance with FAR-25 requirements. Basic safety requirements for systems are in chapter 25.1309 of this regulation. Basic requirements and recommendations are specified in more the detail in the advisory circular AC 25.1309 (European requirements have a similar document, the AMC 25.1309).

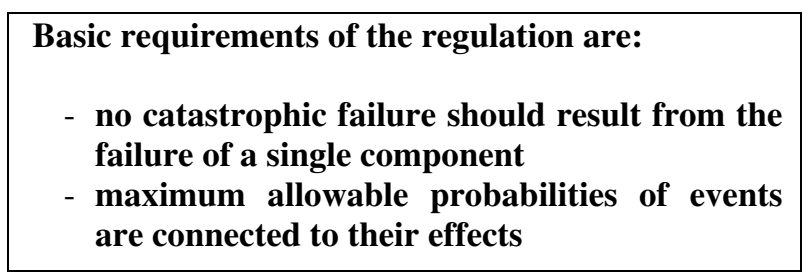

The maximum allowable probability of events with catastrophic consequences for transport category airplanes is $1 \cdot 10^{-9}$ per one flight hour (Tab 2). This value is based on the FAA requirement that the average catastrophic accident rate caused by technical reasons should not be higher than 1 catastrophic accident in $\mathbf{1 \cdot 1 0}{ }^{7}$ flight hours. This requirement was derived from historic accident statistics with the incorporation of goals for the future. Sometimes, different approach is also cited: "a risk arising from the utilization of air transport for passengers should not be higher than normal life risks". This approach is however not included in the regulation. If we consider the overall catastrophic accident rate (caused by technical reasons), $1 \cdot 10^{-7}$ per flight hour and a number of possible failures with catastrophic consequences (let us say hundreds for a transport category airplane), we obtain the requirement for the maximum probability of occurrence for each catastrophic event. This probability should be lower than $1 \cdot 10^{-9}$ per flight hour.

Table 2. Aviation accident rate (Source: National Transport Safety Board, USA)

\begin{tabular}{|l|c|c|}
\hline \multirow{2}{*}{ Type of Operation } & \multicolumn{2}{|c|}{$\begin{array}{c}\text { Accident Rate (per 100,000 } \\
\text { flight hours) }\end{array}$} \\
\cline { 2 - 3 } & 2001 & 2002 \\
\hline Large Air Carriers & 0.24 & 0.24 \\
\hline Commuter & 2.33 & 3.18 \\
\hline Air Taxi & 2.40 & 2.03 \\
\hline General Aviation & 6.78 & 6.69 \\
\hline
\end{tabular}

Note: Accident rates in the table include all causes (technical causes are usually less than $15 \%$ ). 
Requirements for general aviation airplanes (FAR23) have a similar background and structure as requirements for transport category airplanes. In fact, GA airplanes originally had the same requirements and recommendations as transport airplanes (including allowable probabilities), but later it became obvious that requirements for transport airplanes were too strict for GA airplanes. Small GA airplanes have a much higher accident rate than transport category airplanes (in orders of magnitude) and usually limited financial resources for development and certification. It would be senseless to insist on a 100-times lower probability of catastrophic failure for aircraft systems in a category in which the average accident rate is so high. Such an attitude could quickly become a prohibitive element for the development and production of new airplanes (in such a category).

Requirements and recommendations for GA airplanes (listed in AC23.1309) are divided into several classes according to historical experiences. More details are shown on table 3 .

Utilization of reliability analyses during the design and certification stage was not so common for GA airplanes in the past (because of their relatively simple design and systems). However, with the introduction of state-of-the-art avionic systems (including "glass" cockpits, etc.) detailed analyses became necessary.

Table 3. Recommendations of Advisory Circular AC 23.1309 (GA category airplanes)

\begin{tabular}{|c|c|c|c|c|c|}
\hline $\begin{array}{l}\text { Classification of } \\
\text { Failure Conditions }\end{array}$ & No safety effect & Minor & Major & Hazardous & Catastrophic \\
\hline Effect on Airplane & $\begin{array}{l}\text { No effect on } \\
\text { operational } \\
\text { capabilities or } \\
\text { safety }\end{array}$ & $\begin{array}{c}\text { Slight reduction in } \\
\text { functional } \\
\text { capabilities or } \\
\text { safety margins }\end{array}$ & $\begin{array}{l}\text { Significant reduc. } \\
\text { in functional } \\
\text { capabilities or } \\
\text { safety margins }\end{array}$ & $\begin{array}{l}\text { Large reduction in } \\
\text { functional } \\
\text { capabilities or } \\
\text { safety margins }\end{array}$ & $\begin{array}{l}\text { Normally with hull } \\
\text { loss }\end{array}$ \\
\hline $\begin{array}{l}\text { Effect on } \\
\text { Occupants }\end{array}$ & $\begin{array}{l}\text { Inconvenience for } \\
\text { passengers }\end{array}$ & $\begin{array}{l}\text { Physical discomfort } \\
\text { for passengers }\end{array}$ & $\begin{array}{l}\text { Physical distress to } \\
\text { passen., possibly } \\
\text { including injuries }\end{array}$ & $\begin{array}{l}\text { Serious or fatal } \\
\text { injury to an } \\
\text { occupant }\end{array}$ & Multiple fatalities \\
\hline $\begin{array}{l}\text { Effect on Flight } \\
\text { Crew }\end{array}$ & $\begin{array}{c}\text { No effect on flight } \\
\text { crew }\end{array}$ & $\begin{array}{c}\text { Slight increase in } \\
\text { workload or use of } \\
\text { emergency } \\
\text { procedures }\end{array}$ & $\begin{array}{c}\text { Physical discomfort } \\
\text { or a significant } \\
\text { increase in } \\
\text { workload }\end{array}$ & $\begin{array}{l}\text { Physical distress or } \\
\text { excessive workload } \\
\text { impairs ability to } \\
\text { perform tasks }\end{array}$ & $\begin{array}{l}\text { Fatal Injury or } \\
\text { incapacitation }\end{array}$ \\
\hline $\begin{array}{l}\text { Classes of } \\
\text { Airplanes: }\end{array}$ & \multicolumn{5}{|c|}{ Allowable Quantitative Probabilities (per one flight hour) } \\
\hline $\begin{array}{c}\text { Class I } \\
\text { (Typically SRE } \\
\text { under } 6000 \mathrm{lb} . \text { ) }\end{array}$ & $\begin{array}{l}\text { No Probability } \\
\text { Requirement }\end{array}$ & $<10^{-3}$ & $<10^{-4}$ & $<10^{-5}$ & $<10^{-6}$ \\
\hline $\begin{array}{c}\text { Class II } \\
\text { (Typically MRE or } \\
\text { STE under } 6000 \\
\text { lb.) }\end{array}$ & $\begin{array}{l}\text { No Probability } \\
\text { Requirement }\end{array}$ & $<10^{-3}$ & $<10^{-5}$ & $<10^{-6}$ & $<10^{-7}$ \\
\hline $\begin{array}{c}\text { Class III } \\
\text { (Typically SRE, } \\
\text { STE, MRE \& MTE } \\
\text { equal or over } \\
6000 \mathrm{lb} .) \\
\end{array}$ & $\begin{array}{l}\text { No Probability } \\
\text { Requirement }\end{array}$ & $<10^{-3}$ & $<10^{-5}$ & $<10^{-7}$ & $<10^{-8}$ \\
\hline $\begin{array}{c}\text { Class IV } \\
\text { (Typically } \\
\text { Commuter Cat.) }\end{array}$ & $\begin{array}{l}\text { No Probability } \\
\text { Requirement }\end{array}$ & $<10^{-3}$ & $<10^{-5}$ & $<10^{-7}$ & $<10^{-9}$ \\
\hline $\begin{array}{l}\text { SRE - Single Recipr } \\
\text { MRE - Multiple Rec } \\
\text { STE - Single Turbin } \\
\text { MTE - Multiple Tur }\end{array}$ & $\begin{array}{l}\text { ating Engine } \\
\text { rocating Engine } \\
\text { Engine } \\
\text { ne Engine }\end{array}$ & & & & \\
\hline
\end{tabular}

Note: Table does not include Software Development Assurance Levels.

\section{List of recommended analyses}

Recommended analyses used to prove safety and reliability during certification are listed in AC 23.1309 and AC 25.1309. They include:

FHA (Functional Hazard Assessment) - FHA usually includes a list of basic aircraft functions and failure conditions. FHA is systematic and comprehensive examination of functions (during all flight stages). This is a basic document for subsequent detailed analyses. FHA is in most cases mandatory.

PSSA (Preliminary System Safety Assessment) - PSSA is used to complete the failure conditions list and corresponding safety requirements.

SSA (System Safety Assessment) - SSA is systematic, comprehensive evaluation of the selected aircraft system to show that relevant safety requirements 
are met. It usually integrates the results of various analyses (FMEA, FTA, RBD, MA) (Fig3).

FMEA/FMECA (Failure Mode and Effects Analysis/Failure Mode, Effects and Criticality Analysis) - FMEA/FMECA is used to identify failure effects for failures of simple items. "No catastrophic failure condition should result from the failure of a single component"; compliance with this requirement is demonstrated using FMEA/FMECA. Two types of FMEA/FMECA are used in aerospace engineering, part and functional FMEA/FMECA. In the Czech aerospce industry, FMECA was in the past utilized by Aero Vodochody. The former LET Kunovice (now Aircraft Industries) used and EVEKTOR company still uses FMEA extended by failure rate estimates.

RBD (Reliability Block Diagrams) - Sometimes also called DD (Dependence Diagrams). RBDs are used together with FTA and MA to analyse selected complex failure modes (simultaneous failure of multiple items). This usually includes failure modes with HAZARDOUS or CATASTROPHIC consequences. RBDs were frequently used by LET Kunovice and are also used by EVEKTOR, s.r.o (as well as by other aerospace companies).

FTA (Fault Tree Analysis) - FTA has the same purpose as RBD. This method is utilized at Aero Vodochody.

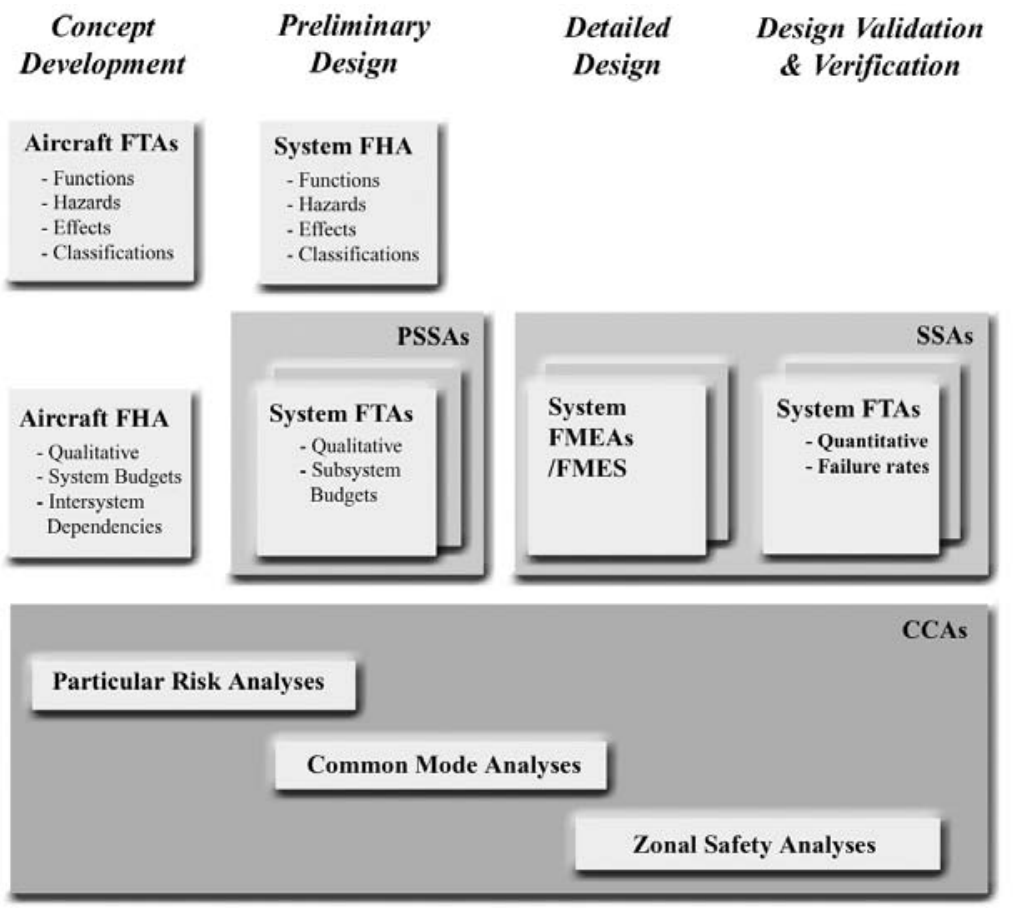

Fig 3. Overview of the Safety Assessment Process (Source: SAE ARP4761)

\section{Major Czech aviation projects}

The Czech aviation industry has traditionally been mainly focused on general aviation aircraft. Over the past
MA (Markov Analysis) - MA is used during the design and certification process for analyses of very complex failures (complex redundant systems, etc.). It is often combined with FTA (Dynamic FTA). It was applied several times by Aero Vodochody. Several works about this topic were also published at the Aeronautical Research and Testing Institute in Prague.

CCA (Common Cause Analysis) - CCA is composed of the following analyses: ZSA (Zonal Safety Analysis), PRA (Preliminary Risk Analysis), and CMA (Common Mode Analysis). The main purpose of CCA is to reduce failure modes arising from dependences between systems.

It is the responsibility of the analyst to choose suitable analyses for particular aircraft (or system). Since the recommendations of the regulation were created for large and complex transport aircraft, it is not necessarily the best option to use all listed analyses, especially for small airplanes. Detailed procedures and implementation of the analyses listed are in related industrial documents. The most important of them are SAE ARP 4754 [9] and SAE ARP 4761 [10]. Other related documents are ref. [8, $7,6]$. 
- Ae 270 Ibis (certified in accordance with Class III recommendations of AC23.1309) All metal, singleengine, 10-seater turboprop. Cruise speed is up to $270 \mathrm{kt}$, range up to $1544 \mathrm{~nm}$.

- VUT100 Cobra (certified in accordance with Class I recommendations of AC23.1309) (Fig 4). All metal, single-engine, 5-seater aircraft with retractable landing gear. The VUT100-131i has a max. takeoff weight of $1450 \mathrm{~kg}$, max. speed of $324 \mathrm{~km} / \mathrm{h}$ and range of $1830 \mathrm{~km}$. Furthermore, the airplane is equipped with advanced avionics and permits IFR flights.

- EV-55 (certified in accordance with Class III recommendations of AC23.1309) (Fig 5, 6). Twinengine utility aircraft with all metal structure (and high-wing).The airplane has nine seats and max. takeoff weight of $4600 \mathrm{~kg}$. The airplane is currently designed and built by EVEKTOR.

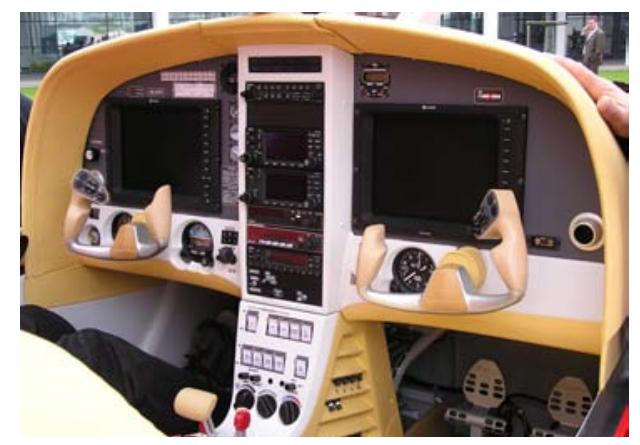

Fig 4. Glass cockpit of VUT100 Cobra

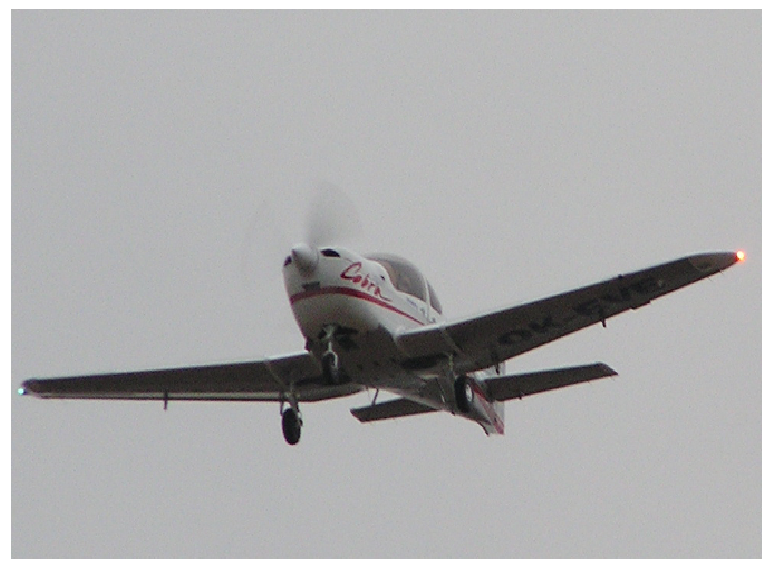

Fig 5. VUT100 is certified in compliance with AC23.1309 Class I (FAR-23)

\section{Brno University of Technology, Institute of Aerospace Engineering}

The Brno University of Technology, with its Institute of Aerospace Engineering (IAE), traditionally supports the activities of the Czech aerospace industry. The growing demand for integration of advanced systems led to the creation of a worksite dedicated to safety/reliability. Equipment and facilities currently available include state-of-the-art software and testing labs for structural (static and fatigue) tests (Tab 4). IAE participated on the reliability assessment of the VUT100 Cobra and EV-55 Outback aircraft.

Since methods for assessing safety/reliability (required by regulation) are not typically used for GA category aircraft design, they often have to be modified. Furthermore, our own reliability research activities are running at the IAE.

An example of such IAE activity is research into the reliability of structural parts. The main aim is to compare the reliability of structural parts designed in accordance with the requirements of Part C and D of FAR-23 regulation (no direct reliability requirements) and systems designed in accordance with Part F (systems and their reliability requirements).

As inputs for the abovementioned research activities, data from fatigue tests were used. Commonly described

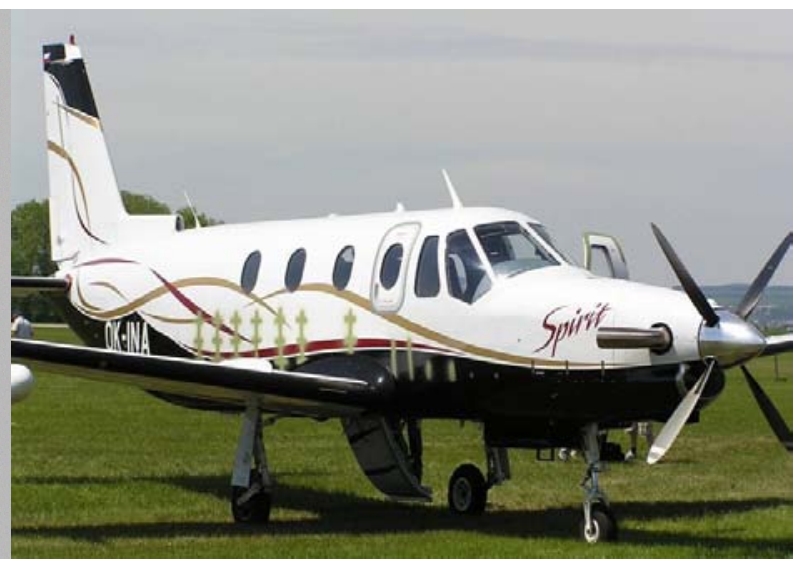

Fig 6. Aero Ae270 is certified in compliance with AC23.1309 Class III (FAR-23)

methods of estimation, including the so-called interference theory, were also used and compared. Some of the outputs are presented on figure 7 .

The results of this research activity indicate that for small GA airplanes, structural parts designed using common design practices have similar reliability levels as systems designed in accordance with paragraph 1309 of the regulation. For higher aircraft categories, fail-safe design (more or less) satisfies the stricter requirements imposed on systems.

Other activities in the field of reliability are oriented towards non-typical applications, including UAVs and hydrogen propulsion. RCM (Reliability Centred Maintenance) and its application in GA are also in the focus of the IAE.

\section{Example of practical assessment of a small GA aircraft}

As mentioned above, the growing complexity of GA aircraft is leading to the utilization of reliability assessment methods. The main driving force in this direction is the effort to enable flying in adverse meteorological conditions and at night and reducing the workload of a crew. New complicated avionic systems are even in small airplanes. 
The electronic avionic system of the small four-seat airplane being assessed included two multifunctional displays with "user friendly" presentation of flight data, navigation information, and aircraft system monitoring. Furthermore, critical flight data had back-up (using mechanical instruments). The airplane permitted IFR flights and optional equipment included autopilot, TCAD, Stormscope and Datalink with actual weather information.
The failure of such an avionic system has catastrophic consequences for an airplane and its crew (especially in bad weather conditions). It is also not possible (because of the complexity and new design) to prove the safety of the new system on the basis of similarity to existing systems.

Methods used for the assessment of mechanical structures:

1. Application of interference theory based on stochastic behaviour of loads and strength of mechanical parts.

$$
R=\int_{0}^{\infty} f_{L}(L) \cdot\left[1-F_{S}(L)\right] \cdot d L
$$

Models of stochastic processes representing loads were based on measurements done during the operation

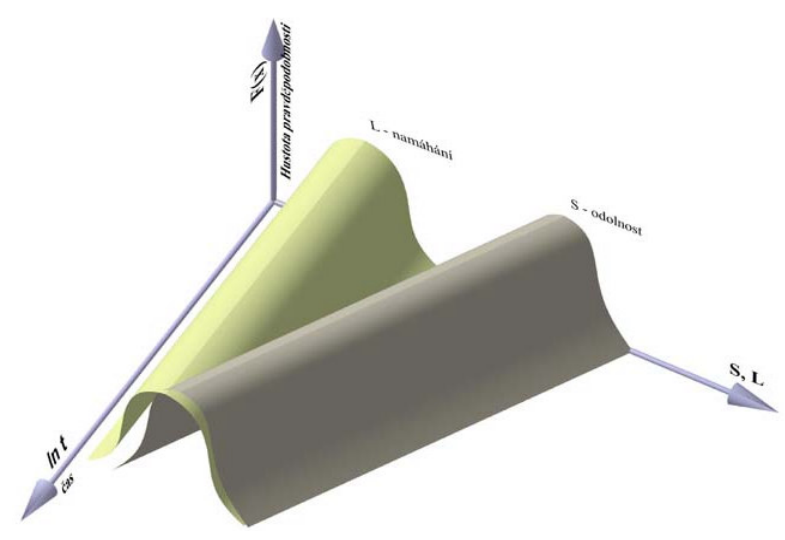

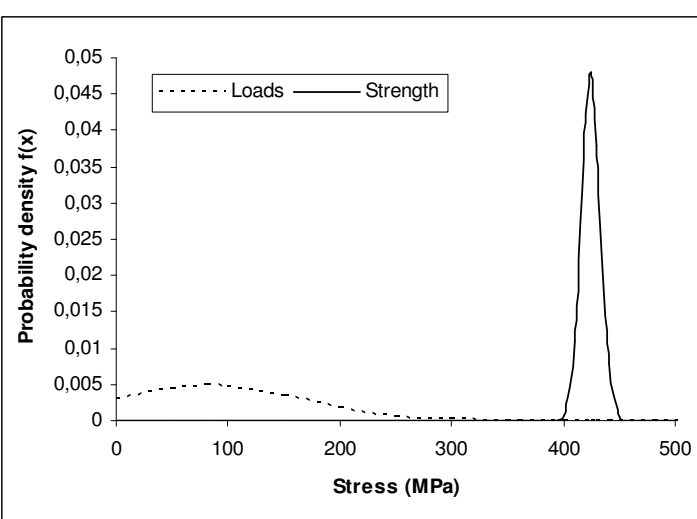

of small sports airplanes (load spectra). This model does not represent completely real life operations, but it is often used for reliability estimates for mechanical structures.

The application proved to have very limited potential for estimation of failure probability (or failure rate) in GA. The reason is in the very low allowable probabilities in regulations. Some potential could be seen for unmanned air and space vehicles and in military applications, however.

The secondary result of this work is a list of the stochastic behaviour of some basic materials used in aviation (aluminium alloys, steels).

2. Evaluation of tests accomplished during development and certification. These static and fatigue tests can be considered as representative in the sense of required actions necessary to obtain certification. The producer is forced to prove the safety of the structure using these tests.

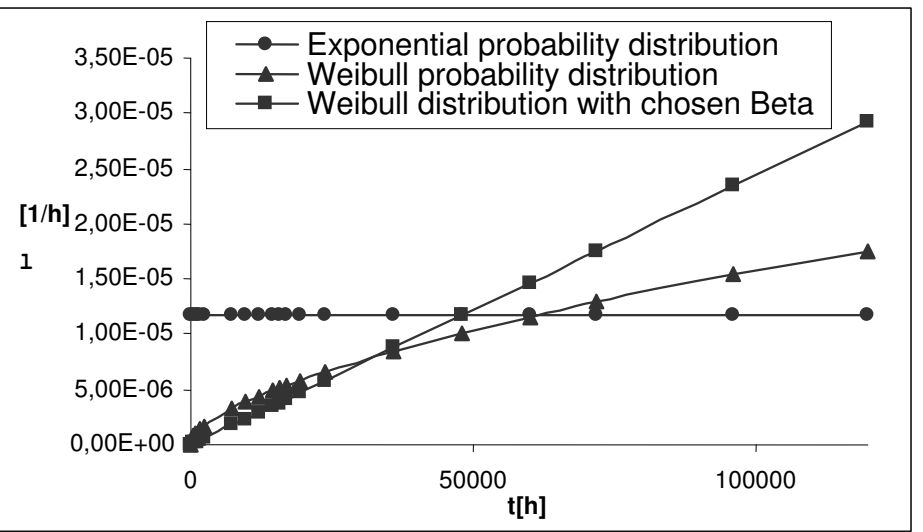

An evaluation of the tests from the point of view of reliability gives basic failure rate estimates for mechanical parts.

Several static and fatigue tests of different structural parts for certification purposes were made at IAE (during certification of real airplanes). Fatigue tests of wing component specimens and engine mounts were evaluated. Conclusions indicated that the producer is forced to prove failure rates in the range of $1 \cdot 10^{-6} \div 1 \cdot 10^{-5} \mathrm{~h}^{-1}$ during such tests.

It would be very difficult (if not impossible) to prove significantly lower failure rates because of the extremely long time of the tests (each of the previously mentioned fatigue tests was three months long).

Fig 7. Reliability levels of structural parts obtained during design and testing phase 
Table 4. Tools for reliability assessment at IAE

\begin{tabular}{|l|l|}
\hline \multicolumn{2}{|c|}{ Tools for reliability assessment available at IAE } \\
\hline Reliability data and prediction procedures & Prediction software \\
\hline MIL-HDBK-217 & Reliasoft BlockSim6.2 FTI (RBD and FTA) \\
\hline RAC NPRD-95C & RELEX Markov \\
\hline RAC FMD-97 & $\begin{array}{l}\text { Evaluation of data (evaluation and planning of reliability } \\
\text { tests) }\end{array}$ \\
\hline RAC PRISM v1.5 & \\
\hline NSWC 98/LE1 MechRel & Reliasoft Weibull++ 6 \\
\hline $\begin{array}{l}\text { RELEX Prediction Module (including Telcordia Bellcore) } \\
\text { Part libraries }\end{array}$ & Reliasoft RGA 6 \\
\hline RAC NONOP-1 (Nonoperating Reliability Databook) & Our own (IAE) software applications \\
\hline Chinese GJB/Z 299B & \\
\hline Furthermore, literature and selected IEC standards are available at IEA. \\
\hline
\end{tabular}

\subsection{Assessment methods}

Analyses used in the safety/reliability assessment included:

FHA (Functional Hazard Assessment)

Failure rate estimates (using data from suppliers, data from MIL-HDBK-217F, NPRD-95, FMD-97, RAC PRISM, etc.)

Part FMEA (more than 100 components of the avionic system were analysed in detail, including assessment of failure effects, SDALs and failure rate estimates-enhancement against standard FMEA). The chosen form of FMEA was close to FMECA (without the criticality assessment).

Functional FMEA

RBDs (complex failures with HAZARDOUS and CATASTROPHIC effects were analysed)

Furthermore, Software Development Assurance Levels (SDALs), defined in SAE ARP4754 [9] and RTCA DO-178 [6], were used. Ref. [9] defines five assurance levels:

A - highest safety level, B, C, D, E - lowest safety level

The indirect effects of lightning strikes and High Intensity Radiated Fields (HIRFs) were also included in the analysis-using requirements and recommendations listed in RTCA DO-160 [6].

\subsection{Data sources}

Usually only limited field data are available for new avionic systems (since they have only very limited operational record). Equipment producers usually provide aircraft producers with design estimates of MTBF for particular equipment. Such estimates are commonly based on MIL-HDBK-217 predictions [5]. No further information (i.e. failure modes and their probabilities) is usually available.

If particular equipment is sold for a significant time period, limited data from warranties may also be available (to verify design estimates).

Few equipment producers provide an aircraft producer with more detailed data. For example, the producer of the NAV/COM receiver for the VUT100 Cobra aircraft was able to provide the aircraft manufacturer with failure rates estimates for several different failure modes. Furthermore, based on its customer repair database, some of the estimates were verified.

The suitability of MIL-HDBK-217 for reliability estimates is widely discussed in the scientific/engineering community. In the case of the NAV/COM receiver, design estimates were rather pessimistic (according to the producer of the equipment).

The range of design estimates from commonly used sources may be very wide. Table 6 shows the range of estimates from MIL-HDBK-217F, RAC NPRD-95 and RAC PRISM. It is responsibility of the analyst to choose the best value for a particular type of aircraft.

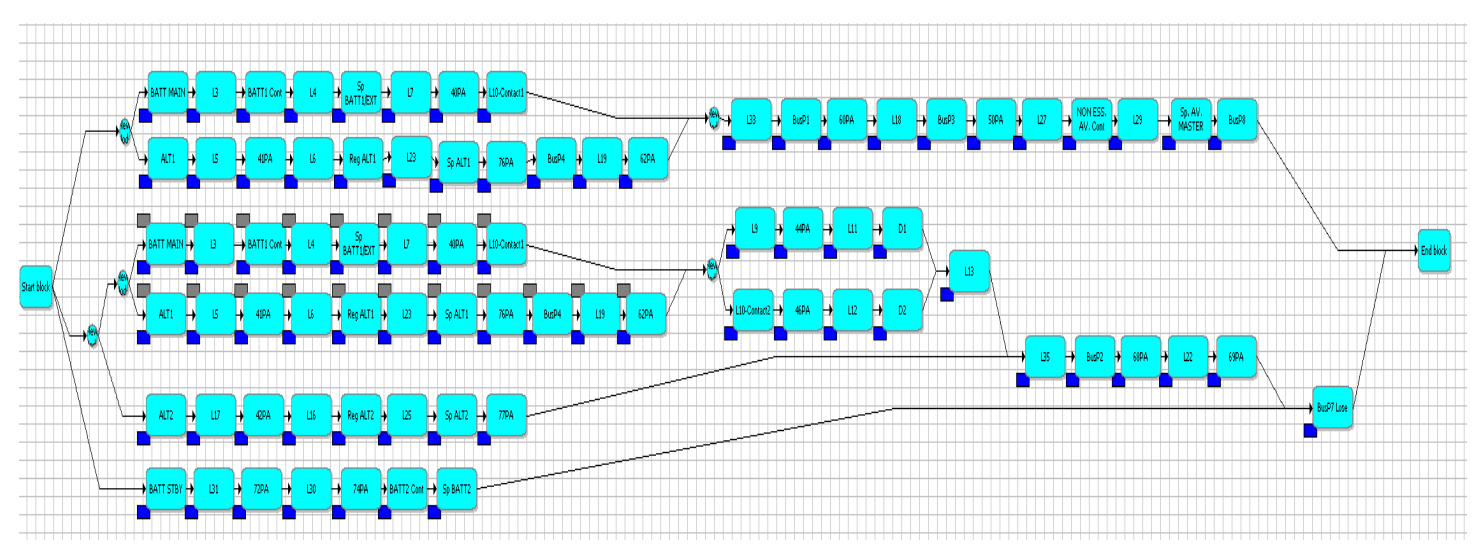

Fig 8. Example of reliability block diagram analysed using BlockSim 6.2 FTI 
Table 5. Example of FMEA (typical FMEA was extended by failure rate estimates and relevant SDALs)

\begin{tabular}{|c|c|c|c|c|c|c|}
\hline Id. & Item & Function & Failure Mode & Failure Effect & $\begin{array}{l}\text { Mode } \\
\text { Failure Rate }\end{array}$ & $\begin{array}{c}\text { Failure } \\
\text { Effect } \\
\text { Classif. }\end{array}$ \\
\hline \multirow{5}{*}{ 妟 } & \multirow{5}{*}{$\begin{array}{l}\text { Multi- } \\
\text { functional } \\
\text { display } \\
\text { MFD }\end{array}$} & \multirow{5}{*}{$\begin{array}{l}\text { Engine data } \\
\text { presentation, } \\
\text { selected } \\
\text { aircraft } \\
\text { systems } \\
\text { monitoring, } \\
\text { navigational } \\
\text { information } \\
\text { presentation. }\end{array}$} & $\begin{array}{l}\text { Complete loss of } \\
\text { information }\end{array}$ & $\begin{array}{l}\text { Execution of emergency procedures. } \\
\text { Significant increase in workload. Failure effect } \\
\text { classification is based on most serious effects } \\
\text { from particular failure modes. }\end{array}$ & $\begin{array}{l}<1,14 \cdot 10^{-5} \\
\mathrm{SDAL}=\mathrm{B}\end{array}$ & MAJOR \\
\hline & & & $\begin{array}{l}\text { Loss of RPM } \\
\text { indication }\end{array}$ & $\begin{array}{l}\text { RPM indication has back-up mechanical } \\
\text { instrument. Exceedance of limits is indicated on } \\
\text { PFD ("engine caution", "engine exceed"). }\end{array}$ & $\mathrm{SDAL}=\mathrm{B}$ & MINOR \\
\hline & & & $\begin{array}{l}\text { False indication } \\
\text { of RPMs }\end{array}$ & $\begin{array}{l}\text { It is possible to identify false RPM indication on } \\
\text { MFD using comparison with back-up mechanical } \\
\text { RPM indicator. Exceedance of limits is indicated } \\
\text { on PFD ("engine caution", "engine exceed"). }\end{array}$ & $\mathrm{SDAL}=\mathrm{B}$ & MINOR \\
\hline & & & $\begin{array}{l}\text { Loss of manifold } \\
\text { pressure (MAP) } \\
\text { indication }\end{array}$ & $\begin{array}{l}\text { Back-up of MAP indication is provided by } \\
\text { mechanical instrument. Exceedance of limits is } \\
\text { indicated on PFD ("engine caution", "engine } \\
\text { exceed"). }\end{array}$ & $\mathrm{SDAL}=\mathrm{B}$ & MINOR \\
\hline & & & $\begin{array}{l}\text { False indication } \\
\text { of manifold } \\
\text { pressure (MAP) }\end{array}$ & $\begin{array}{l}\text { It is possible to identify false MAP indication on } \\
\text { MFD using comparison with back-up mechanical } \\
\text { MAP indicator. Exceedance of limits is indicated } \\
\text { on PFD ("engine caution", "engine exceed"). }\end{array}$ & $\mathrm{SDAL}=\mathrm{B}$ & MINOR \\
\hline
\end{tabular}

Several modifications to the designed system were made based on results of the assessment.

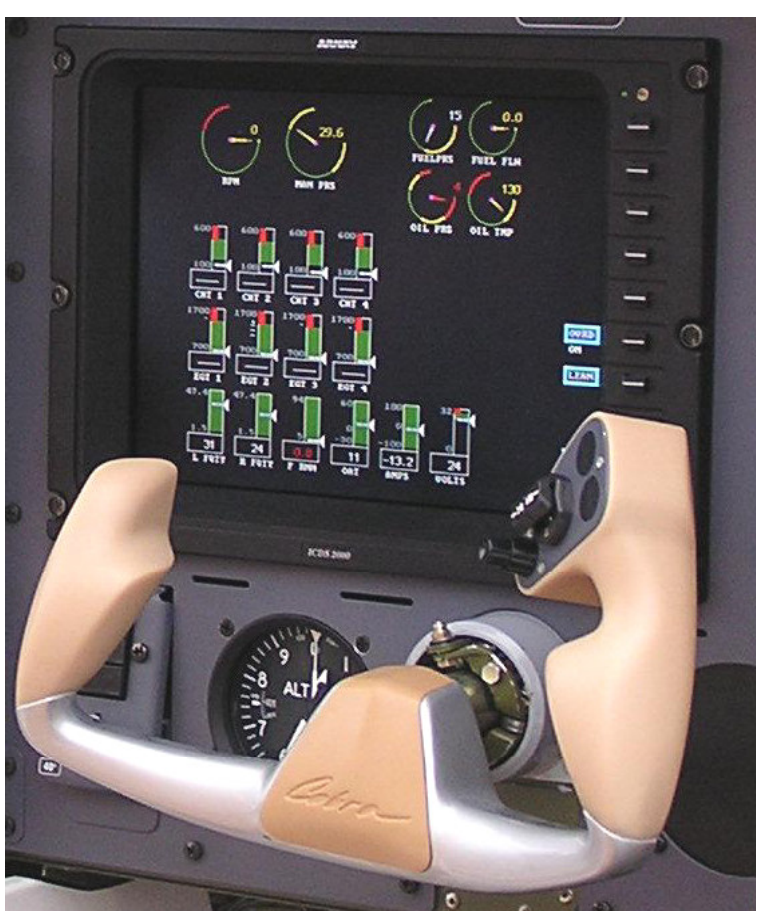

Fig 9. Software interface: graphical presentation of engine/systems data (VUT 100 Cobra airplane)

Table 6. The range of failure rate estimates for selected components (from different sources)

\begin{tabular}{|l|c|}
\hline Component & Failure Rates $\left(\mathrm{h}^{-1}\right)$ \\
\hline Battery, rechargeable, Lead Acid & $2,7 \cdot 10^{-5} \div 1,8 \cdot 10^{-4}$ \\
\hline Alternator & $6,8 \cdot 10^{-6} \div 2,7 \cdot 10^{-4}$ \\
\hline Switch & $1,2 \cdot 10^{-7} \div 1,3 \cdot 10^{-5}$ \\
\hline Contactor (relay) & $2 \cdot 10^{-6} \div 1 \cdot 10^{-4}$ \\
\hline
\end{tabular}

\section{Conclusions}

This paper discussed requirements and recommendations of airworthiness regulations, especially regulations imposed on fixed wing aircraft (FAR-23 and FAR-25). Further, a list of assessment methods used for practical analyses was provided, including a brief summary of their utilization in the Czech aerospace industry. Special attention was paid to the activities of the Brno University of Technology (and its Institute of Aerospace Engineering). A practical example of a system analysed at the IAE was in section 5. Finally, the paper closed with a list of related industrial documents.

The purpose of this paper was to provide the reader with basic insight into practical problems solved in the aerospace industry. The methods that are mentioned are newly utilized for the certification of GA aircraft, at least in the Czech Republic. This enables the development of state-of-the-art aircraft with advanced systems (avionic, etc.).

\section{References}

1. Advisory Circular AC 23.1309-1C. Equipment, Systems, and Installations. Airplanes. Federal Aviation Administration, Washington, D.C. 1999, no. $3,30 \mathrm{p}$.

2. Advisory Circular AC 25.1309-1A. System design and analysis. Federal Aviation Administration, Washington, D.C. 1988, no. 6, 19 p.

3. FAR Part 25: Airworthiness standards: Transport category airplanes. Federal Aviation Administration, Washington, D.C. 7/2002, no. 7. 
4. MIKULA, J. Konstrukce a projektování letadel I [Aircraft Design I]. Praha: ČVUT, 2004. ISBN 8001-03073-3.

5. MIL-HDBK-217F - Reliability prediction of electronic equipment. Washington DC: US Department of Defense, 1991, no. 2, 205 p.

6. RTCA DO-160B [Environmental conditions and test procedures for airborne equipment]. 1997, no. 7.

7. RTCA DO-178B [Software consideration in airborne systems and equipment certification], 1992, no. 12.

8. RTCA DO-254 (EUROCAE ED-80) Design assurance guidance for airborne electronic hardware, 2000, no. 4, 89 p.

9. SAE ARP 4754 Certification considerations for highly-integrated or complex aircraft systems, 1996, no. 11,88 p.

10. SAE ARP 4761 Guidelines and methods for conducting the safety assessment process on civil airborne systems and equipment, 1996, no. 12, $331 \mathrm{p}$.

11. Title 14 Code of Federal Regulations (14CFR) Airplanes: Airworthiness Standards: Normal, Utility, Acrobatic, and Commuter Category Airplanes. Washington, D.C.: Federal Aviation Administration, 2002, no. 7 . 